\title{
Information needs in drugs prevention initiatives: establishing and evaluating a service
}

\author{
KAY FLATTEN \\ School of Information Studies \\ University of Central England \\ and \\ LYNNE SPEAKE \\ BA(Hons) 3rd Yr \\ School of Information Studies \\ University of Central England
}

\section{Summary}

This article describes a Home Office funded project to establish an information service within a local drugs prevention initiative and to evaluate its effectiveness a year later. The article focuses on building the library, targeting information, identifying channels of distribution, and evaluating the project. The lessons learned are offered as guidelines for others wishing to establish a drugs prevention information service.

\section{Introduction}

The Birmingham Drugs Prevention Initiative (BDPI) was one of 20 Home Office initiatives in the UK, charged with working with communities to reduce drug related harm. The Initiative had a team comprising Director, a Senior Development Worker, a Parents Project Coordinator and a Secretary. This team was committed to the provision of information for use by their ongoing projects and by the Birmingham community. The actualization of that commitment was enhanced when the Home Office Drugs Prevention Initiative contracted the Centre for Information Research and Training (CIRT) to establish an Information Service. The contract included:

- $\quad$ establishing a library of resources;

- $\quad$ building computer databases;

- delivering information;

- $\quad$ evaluating its effectiveness.

This article details the challenges faced and lessons learned in establishing and running the information service over the 12 months of 1994.

\section{Building the library}

The Centre for Information Research and Training is affiliated with the School of Information Studies at the University of Central England (UCE). CIRT research staff are qualified librarians. For the first three months of the contract, a CIRT researcher worked to order a selection of leaflets, comics, poster, cards, computer games, videos, training packs and books. The BDPI team members advised on the selection of resources based upon their own needs and knowledge of people they serve.

While waiting for the resources to arrive the researcher designed two databases using Cardbox computer software. These databases were:

- Resources - comprising a bibliographic record for each title including abstract and evaluation fields;

- Others - comprising details of other organizations which provide drugs prevention information and services.

As resources arrived they were entered onto the databases. By the end of the three months there were 500 titles on the "Resources" database and 130 on the "Others" database. 
CIRT then helped to select a Library and Information Studies Placement Student from UCE. The student was trained on how to run the service for her nine month placement. She also faced the remaining challenges of targeting customers, continued selection of resources and distributing information effectively.

\section{Targeting customers}

The placement student worked to identify the various groups of people needing BDPI resources and she subsequently outlined their information needs. She found the following three groups needing drugs prevention information:

- $\quad$ the public;

- $\quad$ the middle agents (teachers, youth workers);

- director and workers in the BDPI office.

The Birmingham public has differing ethnic, religious, and age parameters. They demanded information on specific topics of personal interest. The complexity of their enquiries necessitated the monitoring of requests in order to predict what information to have on hand. Enquiries from the public were often preceded by an article in the press. The placement student prepared for these incoming calls by assiduously scanning the local and national press. The public often appeared not to understand the difference between drugs prevention and drugs treatment. Many requests were ultimately redirected to external organizations using the "Others" database.

The middle agents were the group with the greatest potential impact on drugs education. These teachers and youth workers regurlarly interacted with young people, their job necessitating an information support service geared to the interests and needs of young people. These middle agents were less likely than the public to have the time to come to the BDPI office. Visits to their places of work was of fundamental importance to the success of the service.

The placement student did not work in isolation. She actively worked alongside other BDPI staff in shaping the direction of service provision and reacting to information needs within the office. The role of information in enabling the team to successfully complete their day to day operational activities was crucial. Therefore a thorough understanding of each team member's job was ongoing.

At BDPI it was the team members who guided the process of selecting information products of interest to the other service users. The Senior Development Worker and Parents Project Coordinator had a keen sense of what would and would not work with selected audiences. Acquiring the right products was dependent upon their knowing the people served.

This process of knowing the groups and people served and then selecting the information products accordingly comprised the targeting work of the placement student.

\section{Targeting information products}

The service delivered information loosely grouped into two product types. These were:

- information designed for use with teenagers and young adults

- information in the form of referrals

Products for teenagers and young adults

Drugs prevention work must keep abreast of fads and cultural trends. The researcher and placement student qualitatively analyzed the information products designed for some groups of young people and found that 
they contain these traits:

- "flashiness" with multicoloured bright images;

- angular designs often implying action;

- $\quad$ short and pointed messages;

- images matching the topic for relevance;

- $\quad$ direct speech with street slang;

- $\quad$ rude, bare facts, often crude;

- humour.

The researcher and placement student therefore selected posters, leaflets, postcards, fact sheets, comics and games with these qualities in an attempt to attract young people to the products. It was intended that each item would reflect the tastes and attitudes of the young adult generation.

There were obvious problems with selecting such products. Druglink magazine's September/October 1993 cover showed a Mike Linnell Fiona cartoon containing contrasting female images. The resulting uproar implied that sexist, homophobic, offensive messages were used. No doubt Mike Linnell (artist), Mike Ashton (editor), and the Institute for the Study of Drugs Dependence (ISDD) managers anguished over the decision to print that cover. However, it is just that sort of 'on the edge' product which the BDPI Information Service sought to include as part of its stock. Much drugs use is not "politically correct" so information to prevent their abuse may not be either.

There were also problems surrounding the dynamic packaging and direct messages of information products. The researcher and placement student interviewed other team members to identify the audiences most likely to use a new product and the audiences most likely to take offence. The database record of the item included an abstract field which mentioned these points. Teachers and youth workers were forewarned to prevent potentially offensive material from causing problems.

As well as selecting products, BDPI also generated their own. One such product was the comic series by Drug Free House. These were publications with comic relief and hard hitting facts. The Service also collected T-shirts and small items like pencils and buttons to give away on outreach trips. Whenever possible, the researcher and placement student acquired products which matched the BDPI strategy.

\section{Referrals as products}

Referring enquiries to other information sources is a significant component of information work and the BDPI Information Service was no exception. Two of the most frequent referrals were to the Institute for the Study of Drugs Dependence and the Birmingham Health Education Unit (part of Birmingham City Council Education Department).

The range and complexity of information from other agencies made them the cornerstones of the service. These organizations provided the products for the BDPI Information Service to distribute. Directory information ie. obtaining and updating information about such organizations and ordering, cataloguing and storing their products was a significant element of the Information Service work. The shelving plan at the service was partially arranged by organization name. 


\section{Channels of distribution}

The main channels of distribution for BDPI stock were:

- $\quad$ youth centres

- $\quad$ schools

- community groups

- $\quad$ organizations dealing with health education and promotion

- $\quad$ other libraries and information centres

- exhibitions

- $\quad$ individuals visiting BDPI

Of these categories, more materials were disseminated to youth centres than to any other group.

Due to the sensitive nature of drugs information, it was not acceptable to simply 'hand out' materials without advice as to their uses. The BDPI Director emphasized the need for literature to be viewed within the wider context of drugs education and encouraged active communication between the placement student and Service users. BDPI staff were also available to advise the student on matters such as drugs policy and related issues. In this sense, the researcher identified the Service as a cooperative effort.

It was important for the placement student to be proactive in presenting the service to both existing and potential users, with outreach work taking up approximately $50 \%$ of her time. Most clients requested guidance in selecting literature, but were reluctant to visit the BDPI offices. In response to these needs, visits were arranged to schools, youth groups, health education agencies and libraries. Youth workers required the most help in selecting appropriate materials for drugs education sessions and were reluctant to try 'newer' resources, such as games and activity packs, unaided. At the end of each visit, the organization was given the opportunity to place orders for any materials they required.

The placement student also responded to requests to give talks to specific groups such as community police officers. Contacts made at the talks widened the network for potential dissemination of information. In addition, the Information Service interacted with other organizations involved in drugs education, for example by providing information packs to support a theatre group working in the field of drugs prevention.

Finally, resources from the Information Service were used in exhibitions and displays throughout Birmingham during European Drugs Prevention Week. An information stall was also set up at the International Conference Centre during the 'Take care and through care' conference.

\section{Conclusion}

The evaluation of the service at the close of the year revealed significant factors. Foremost was the need for the service to market itself. In-house use of the resources was rare. The placement student offered two suggestions to improve the service. These were:

- Hire an information worker with social work experience - the work environment will be in the field not in the library

- $\quad$ Equip a mobile van to take selected resources to people - money spent on attractive displays and shelving inside the drugs prevention office would be better spent in decorating the van.

The UCE researcher analyzed the two databases for frequency of use per entry and evaluative comments 
added to the record. She also analyzed records of telephone calls, post enquiries and in-house visits. Twenty per cent of these customers were mailed a questionnaire asking if their information need was met, if so how, and for comments concerning satisfaction with the product and the information process. The responses indicated the people using the Information Service were well pleased with both the product and process. However, the research assessed these responses in light of the low levels of demand for information and offered suggestions to the Home Office and BDPI. These suggestions are listed below for anyone wishing to establish a drugs prevention information service.

1. People are not as likely to come to the service, therefore minimize appearance and display features while maximising telephone access, fax and possibly email.

2. People prefer information that has visual imagery, short catchy layout, is frank and transparent, and is free.

3. Customers must be 'made to happen', meaning the service must be advertised extensively, with the telephone number prominent.

4. People vary in how comfortable they feel about drugs facts: therefore collect a range of conservative and bold approaches.

5. People should be educated on how best to use the information and how to avoid problems.

6. People can be served by referral to another organization, thus requiring a rich database and knowledge of the drugs education network.

7. People may already have access to drugs prevention information from another organization so capture an unserviced part of the community.

8. People expect the information worker to be knowledgeable in social work practices.

9. People want the information worker to bring the information to them. Do so to establish initial group contact.

10. People need an information worker, not a librarian, so avoid overdoing the in-house details and neglecting the outreach.

The above mentioned guidelines focus upon the customer. The most important finding in this project was the need to build a customer base alongside a collection of wide ranging resources to suit the needs of these customers.

As of 1 March 1995, the BDPI office will combine with the Wolverhampton Drugs Prevention Team. This larger remit increases the need for networking and outreach. Due to the reorganization of the Drugs Prevention Initiatives within the UK, further requests about this project should be directed to:

Central Drugs Prevention Unit

Home Office

Room 354

Horseferry House

Dean Ryle Street

London

SW1P 2AW 


\title{
References
}

1. Colombia, $\mathrm{M}$ et al. Quality assurance in drug information centres. Online CDROM Review, 17 (5), 1993 p279 - 284.

2. Nixon, J. Factline '91: an evaluation of a drugs information campaign in Brighton. Brighton: University of Brighton. (Drugs Prevention Initiative), Occasional Paper, 1992.

3. Murphy, S and Smith, C. Crutches, confetti or useful tools? Professionals views and the use of health education leaflets. Health Education Research, 8 (2), 1993, p $205-215$.

\section{Developing the flexible library and information workforce}

\author{
ANNE GOULDING and EVELYN KERSLAKE \\ Department of Information and Library Studies, \\ Loughborough University
}

\section{Introduction}

Flexibility is a vaguely defined media buzzword connoting the progressive, forward-looking workplace. Employers report that increased labour market flexibility has made them more cost-effective, efficient, better able to deal with customer and employee demands and the implementation of new technology. But what is happening to those workers who make up the flexible workforce? For a while in the 1980s it seemed that flexibility could do no wrong; now, however, the shortcomings of flexible labour markets are becoming more apparent.

Recently, concerns abut the longer term implications of a flexible workforce have been raised by organizations as varied as the CBI and NIACE (the National Institute for Continuing Adult Education), particularly in relation to impact of the flexible workforce on the overall skills profile of the labour market. Recent work suggests that 38.2 per cent of all workers in the UK are flexible workers so, with such a significant proportion of the labour market in flexible employment, where does responsibility lie for providing and paying for their training and development?

Currently, employers seem willing to invest in training and development primarily for their permanent, fulltime workers. ${ }^{1}$ However, continuing to ignore the training needs of flexible workers could endanger any benefits gained with increased flexibility. Failure to train flexible workers might perhaps contravene sex discrimination legislation too. After the House of Lords decision, in late 1994, that discrimination against part-time workers was discrimination against women, as well are the great majority of part-time workers, a similar interpretation could apply to the training of flexible workers, who are also mostly women.

\section{Flexibility and library and information services}

Library and information services are no strangers to flexible working patterns - the widespread use of extended opening hours with varying workloads ensures this. A study of UK library and information services funded by Loughborough University's School of Education and Humanities earlier this year (1995) demonstrated the significant incidence of flexible workers in this area. The study involved public, academic and special libraries in a postal questionnaire survey which had a response rate of 57 per cent. It found that of 38,000 workers in 475 organizations responding to the survey, 40 per cent were flexible workers, and that flexible working patterns were found in all library types and among professional and support staff. Flexible workers were defined as those workers who were on permanent part-time, temporary part-time, job share, annual hours, term time only, temporary full-time and homeworking contracts. 